\title{
The impact of demographic and situational factors on training transfer in a health care setting
}

Research Article

Mary C. Cowman ${ }^{1}$ and Alma M. McCarthy*

'Department of Health, Sport and Exercise Science,

Waterford Institute of Technology, Ireland

2J.E Cairnes School of Business and Economics,

National University of Ireland, Galway, Ireland

\begin{abstract}
Training transfer is the extent to which human resource development (HRD) interventions result in a change in trainee workplace behaviour post-training. Training transfer is an important dimension of training effectiveness. However, studies on training transfer are not extensive and some of the findings are inconclusive. Drawing on a study of 124 trainees across 102 similar organisations within the Irish health care system, the current study investigates the effect of demographic variables (age, educational background, position), situational variables (time since training, tenure, recruitment to the training programme, preparation for training) and organisational size on training transfer. Regression analyses report that current position significantly impacts training transfer in terms of direction, while method of recruitment to the training programme, age and employment tenure were all significant predictors of training transfer complexity. The findings report that age is not a barrier to training transfer. These results have important implications for HRD practitioners with regard to the profile of the workforce in this setting, the training and development function and trainee recruitment.
\end{abstract}

Keywords: human resource development; health care sector; training transfer

(C) De Gruyter Open Sp. z 0.0 .

\section{INTRODUCTION}

There are major forces within the health care industry which require organisations to seek innovative ways to deliver health care more efficiently and effectively. Sambrook and Stewart (2007) state that UK health policies and practices are being developed to address the challenges of increased demand and pressurised supply created by finite resources, emerging technologies and ageing populations. In the Irish context, health care organisations are facing challenges and burdens as a consequence of the recent difficult economic climate including fewer staff, reduced budgets, increased workload and rationalisation of services (Curtis, 2010). The Future Health: A Strategic Framework for Reform of the Health Service 2012-2015 report detailed the actions to deliver 'the most fundamental reform of our health services in the history of the State' in Ireland (Department of Health, 2012: i). The report refers to the human resource changes required to effect the reforms including 'the right mix of staff, training and up-skilling the workforce, and providing for professional and career development' (p. 47). Managing the professional and clinical workforce within this challenging climate requires effective deployment of appropriately skilled personnel (Conway et al., 2006). The challenging environment has implications for human resource development (HRD) and for workforce planning in the health care sector.

Bartlett (2007) argues that HRD issues associated with the changes within the health sector are often overlooked and Sambrook and Stewart (2007) argue that there is a dearth of theoretical or empirical material concerning learning and development in the health care sector. While a range of training and development programmes are delivered with the objective of enhancing employee skill and performance, ensuring that learning acquired on training programmes is subsequently transferred and utilised in the workplace remains of critical importance for HRD researchers and 
practitioners (Burke and Hutchins, 2008). Nonetheless, where training success is defined as contributing to enhanced individual and organisational performance, some studies have reported that typical organisational training programmes are only achieving about a 10\% success rate (Brinkerhoff, 2005; Saks and Belcourt, 2006). According to Saks and Belcourt (2006: 629), 'transfer is the primary leverage point by which training influences organisational-level outcomes and results'. Furthermore, Hutchins (2009) states that a review of evaluation benchmarking data indicated that organisations reported trainees applied less than $40 \%$ of knowledge and skills obtained from training when measured 90 days post-training. Wexley and Latham (2002), cited in Valeda et al. (2007), found that immediately post-training, approximately $40 \%$ of training is transferred, falling to $25 \%$ at six months and $15 \%$ at 12 months post-training. These figures suggest that the time and money invested in the training intervention may never be fully realised. Consequently, an understanding of the factors affecting training transfer to the workplace is necessary, if the effectiveness of training and development programmes is to be increased. Clarke $(2002,2007)$ argues that very little empirical research on training transfer has been conducted in human service organisations. Furthermore, according to Conway et al. (2006), Keogan (2006) and Clarke (2002), there is a lack of in-depth evaluation studies on factors affecting training effectiveness and the transfer of training in the health care sector in particular.

The current study sought to address the gaps identified in the literature by exploring training transfer over time utilising a training intervention in a health care context. The training intervention under investigation is a training programme to equip nursing and care staff with the skills for enhancing residents' physical activities within long-stay facilities for older adults. The objective of the training is to provide relevant nursing and care staff with the skills, knowledge and abilities to design, deliver and evaluate effective physical activity programmes for older residents/ patients in long-stay facilities. Drawing on training and development evaluation and effectiveness theory, the study explores how demographic variables (age, educational background and position), situational variables (time since training, employment tenure, recruitment to training, and preparation for training) and organisational size affect the direction and level of complexity of training transfer post-programme. Implications of the study for HRD practitioners, for the health care sector and for future research are discussed.

\section{LITERATURE REVIEW AND CONCEPTUAL FRAMEWORK DEVELOPMENT}

\section{Defining training transfer}

Transfer of training can be defined as the application of learned knowledge, skills and attitudes to the job and their subsequent maintenance over time (Cheng and Ho, 2001). Chiaburu and Tekleab (2005) define training maintenance as the reproduction of trained skills in a new setting and training generalisation as the adaptation of trained knowledge and skills to a more complex task situation. Decisions on training policy and training programme provision are based on the belief that learning is transferable and that it is maintained over time. Training transfer is the ability to apply learning from the artificiality of the training course to practical workplace application. Therefore, effective training programmes will aim to enhance subject knowledge and create new knowledge. Training programmes will integrate a variety of learning strategies to enable the competent learner identify and construct relationships between new and old knowledge or adapt existing knowledge to the demands of new, unfamiliar problems. These capacities have the potential to contribute to growth in organisational competitiveness and value in both the short and long term.

Van der Klink et al. (2001) argue that the transfer of training can take many forms and identify three dimensions of transfer: the direction, the level of complexity and the distance. An understanding of these forms is important for evaluation studies measuring the extent of training transfer. Direction refers to either positive transfer (where training leads to desired performance) or negative transfer (where it fails to produce the intended job performance). In terms of complexity, lateral transfer refers to the learner being able to achieve a task at the same complexity level as the task already mastered, whereas vertical transfer refers to the ability to apply learning to similar or more complex skills. In relation to enhancing organisational value or productivity, it is vertical and far transfer which encourages the skills of creative thinking, problem solving and the ability to adapt to changing circumstances. Regarding distance, near transfer refers to training in tasks that are similar or equal to the learner's job tasks. Far transfer is where there is a lack of similarity to the job tasks and training focuses on understanding and the application of principles or rules. Lave and Wenger's (1991) concept of situated learning closely aligns with the concept of distance where they argued that adult learners learn most effectively when there is as close a match as possible between the learning environment 
and context and its application at work. The dimension of transfer desired will depend on the aim of the training intervention. For the purposes of this study, the impact of demographic, situational and organisational factors on the direction and complexity levels of training transfer were explored as these levels were the most relevant to the intervention under investigation.

\section{Demographic, situational and organisational factors and training transfer}

Baldwin and Ford (1988) classified influences on training transfer into three categories: trainee characteristics, training design factors and work environment factors. With regard to trainee characteristics, the majority of empirical studies reported in the literature have focused predominantly on trainee personality factors (Colquitt et al., 2000; Warr and Bunce, 1995), trainee ability (Colquitt et al., 2000) and motivational factors (Santos and Stuart, 2003). According to Van der Klink et al. (2001), trainee characteristics account for most of the variability in training transfer. However, empirical research has not reached a consensus on how a number of demographic variables relate to transfer (Chen et al., 2006). Consequently, Tharenou et al. (2007) suggest that research is required to examine the effect of the type of employees trained and how these factors impact training transfer and subsequent performance.

\section{Demographic variables}

Van der Klink et al. (2001) report that there has been mixed results from studies exploring the effect of trainee age on training transfer. Citing Hastings (1994) report that older trainees experienced more difficulty applying training content to the job. Older adults have also shown less mastery of training material than younger adults (Chen et al., 2006). Conversely, however, Thijssen (1996), cited in Van der Klink et al. (2001), found older trainees with a broad variety of work experiences showed fewer problems achieving training goals and face fewer problems with the application of training to the job. As a result of these contradictory findings, the variable employee age was selected to investigate its effect on training transfer in the current study.

Chen et al. (2006) state that research testing the effect of educational level on training effectiveness has been sparse, although human capital theory suggests that education and training has an effect on learning outcomes and job performance. Chen et al. (2006) report that adults' prior experiences will significantly affect learning. Dorsey et al. (1999), cited in Chen et al. (2006), suggest that certain types of prior experience have a significant relationship with post-training performance. More specifically, Lim and Johnson (2002) found that the degree of transfer was greatly influenced by the individual's technical skills at the start of the programme. Given that there is a dearth of research regarding the effect of employee educational/trainee background on training transfer, this variable was selected for the study on the basis that members of the sample base were divided according to two different educational backgrounds (nurses and Health Care Assistants (HCAs)) reflecting differences in their level of training, qualification and skill base. Rondeau et al. (2009) state that health care organisations in most developed countries are experiencing unprecedented shortages of registered nurses and these shortages are expected to persist into the future. The reduction in staff numbers and the recent moratorium on staff recruitment in the Irish public sector, this has implications for more effective use of exiting staff. Martinez and Martineau (1998) suggest that cost savings may be made through the use of different staffing grades. According to Brady (2010), in any organisation there will be a variety of people with different levels of education, experience and competence that contribute to the delivery of health care. McKenna et al. (2004) suggest that one of the main arguments for increasing HCA numbers in the Irish health care sector was to enable registered nurses to use their time to provide higher level clinical care and delegate less onerous care tasks to HCAs. Consequently, the variable trainee background, which in this study refers to either qualified nurses or health care assistants, was investigated in this study for its potential effect on training transfer.

Chen et al. (2006) argue that transfer research investigating the relationship between job function and transfer of learning is scarce. They argue that different jobs represent different roles and functions within an organisation and these differences may alter trainees' perceptions about the applicability or transferability of skills learned. Consequently, employee position or job role has the potential to influence training transfer and was considered in this study on the basis that members of the sample group used in the study represented several different job positions within their employer organisation. For example, although HCAs represent one of the two groups categorised in terms of trainee background, HCAs may be appointed to three different roles in this setting: (i) general position of health care assistant or to more specific roles including (ii) activity co-ordinator or (iii) assistant to the physiotherapist. 


\section{Situational variables}

Donovan et al. (2001) found that employment tenure was relevant to training transfer levels. For example, employees who had more years of experience in the organisation were more prepared for training, believed content to be more relevant and experienced more opportunities to transfer. According to Bartlett (2007), however, the health care sector is characterised by high job turnover and therefore previous findings may not be generalisable to the sample population used in this study. Consequently, employment tenure was selected for investigation in the current study.

Saks and Belcourt (2006) found in a survey of 150 organisations that less than $50 \%$ of employees successfully transfer knowledge and skills 6 months post-training. This would suggest that a decline or cessation in training transfer is inevitable in the long-term. Cheng and $\mathrm{Ho}$ (2001) argue that research into long-term training retention is important if individual and organisational performance is to be maintained. For example, if differences in the level of transfer can occur with time, as suggested by Saks and Belcort (2006), it is important to develop an understanding of the factors influencing long-term training retention so that intervention strategies can be implemented when required. Therefore, this study investigates the effect of time since training on the level of training transfer.

Tannenbaum et al. (1991) found that trainees who received adequate information and a clear rationale for the training programme from employers reported greater motivation to attend and learn. Trainees unhappy with preand post-training activities were more likely to return to established practices, whereas those who perceived training as leading to higher reward were significantly more likely to transfer training to the workplace (Santos and Stuart, 2003). This study investigates how preparation for training impacts on training transfer. Given that the employee sample group were working across 102 organisations and consequently reporting to different managers and line manages, it was expected that experiences in terms of preparation would vary accordingly.

Motivation to transfer is also influenced by choice in attending training (Elangovan and Karakowsky, 1999). Gregoire et al. (1998) suggest trainees who volunteer for the training are more likely to view the content of the programme as relevant. In relation to recruitment for training, Hicks and Klimoski (1987), cited in Russ-Eft (2002), found participants with a high degree of choice achieved higher test scores and reported more learning than those with low degree of choice. However, Russ-Eft (2002) argues that whilst some authors found voluntary participation leads to better results, some voluntary participants may be difficult to motivate if training requires some additional personal effort or is perceived as involving assessment. This study considered recruitment methods for the training intervention in terms of level of choice experienced by employees in attending the training and its effect on training transfer.

Long-term residential care settings in Ireland vary considerably in terms of size, reflected by the number or residents they accommodate. Whilst Clarke (2007) suggests that organisation or unit size can influence the level of support for reinforcement of training. Clarke (2002) suggests that larger facilities tend to have more resources which may influence ability to transfer training. Consequently, organisation size was investigated for its influence on transfer. Figure 1 below depicts the independent variables explored in the current study to further our understanding of training transfer.

\section{METHOD}

\section{Method of inquiry}

A cross-sectional survey utilising questionnaires with open and closed questions was adopted to gather data from subjects with different demographic and situational characteristics.

\section{Training intervention under investigation}

The intervention utilised for the purposes of the study was an accredited 60-hour training programme designed specifically for the health care sector and the subsector being investigated. The training provided participants with the knowledge and skills to develop physical activity programmes appropriate to the needs of residents in longstay facilities for older adults, the setting in which this investigation takes place. The objective of the training was to provide relevant nursing and care staff with the skills, knowledge and abilities to design, deliver and evaluate effective physical activities for older residents/patients in long-stay facilities. 


\section{Sample and procedure}

The sample group used for this study was the 204 public sector employees who completed the training intervention across 15 courses and 102 organisations. Questionnaires containing both quantitative and qualitative items were mailed to the 204 participants/employees sometime after completing their training programme. A total of 124 usable surveys were returned representing a response rate of $61 \%$.

\section{Measures \\ Independent variables - demographic, situational and organisational factors}

Age. Employees were asked to indicate their year of birth. The data was recoded into two formats for analysis: age in years (continuous variable) and categories to enable comparison between groups (group $1=20-39$ years; group $2=40-49$ years; group $3=50$ years or more). The age group categories have been chosen to broadly align with early career mid-career and late career phases as well as ensuring adequate numbers in each category to allow for statistical interrogation.

Background. Background refers to respondents' level of education and qualification at entry level employment and their eligibility for a specific type of position with corresponding duties, responsibilities and autonomy. Background was divided into two general categories: Nurse or Health Care Assistant (HCA).

Employment Position. Position refers to the job role or employment position held by the respondent at the time of completing the questionnaire. It is recognised that within the two broad categories of employee background, respondents may have different roles within their workplace which has the potential to influence transfer training and training outcomes. Employees were asked to indicate their position from four options: nurse, HCA, physiotherapy assistant or activity co-ordinator. The data was recoded into two categories for analysis: group $1=$ activity coordinators and physiotherapy assistants; group $2=$ nurses, HCAs and other relevant job titles. Allocation to groups was made on the basis of positions believed to be most associated with the more specific duties of physical and general recreational activity provision (group 1) compared to positions involved in the provision of nursing and general healthcare (group 2).

Time since training. The time period that elapsed since the respondents engaged in the training intervention ranged from 6 to 60 months. This data was gathered from the trainers' records and was divided into five subcategories representing discrete time periods since completion of training: $<2$ years; 2-3 years; 3-4 years; 4-5 years; and $5+$ years. Due to the small sample size, the data was re-classified further into two categories for the purposes of regression analysis. In this instance, group 1 refers to those who completed their training between 6 and 36 months previously and group 2 refers to those who completed their training between 37 and 60 months previously.

Employment tenure. This variable was measured using a single closed question asking employees to indicate how many years they have been employed in their current organisation. This data was utilised both as a continuous variable and was also recoded into three employment tenure categories to enable comparison between groups (group $1=$ up to 10 years, group $2=11-20$ years, group $3=21$ or more years).

Recruitment method for the training intervention. Recruitment method for the training intervention was measured in a single closed question providing employee respondents with two options to select one: 'I volunteered' or 'I was approached by my line manager/manager'.

Preparation for training. Employees were asked if they had received all the information they needed about the intervention before training commenced. The forced responses were in a 'yes' or 'no' format.

Organisation size. Organisation size refers to the average number of older adult residents in the organisation or unit at any one time, measured with a single closed question. This data was utilised as a continuous variable and was also recoded so that respondents were allocated to one of two categories to enable comparison between groups: Group = up to 49 residents; Group $2=50$ residents or more.

\section{Dependent variable - transfer of training - direction}

Delivering sessions. This variable sought to establish if respondents were currently delivering activities and exercise regimes for the older adult patients in the long-stay facilities. Respondents were required to tick either a yes or no option to the question 'are you currently delivering the physical activity sessions covered on the course within your organisation'.

Delivering regularly. Regular delivery was defined as delivering a minimum of one session per week. This variable was established from the question 'how many sessions would you deliver most weeks?' The data was 
recoded so that respondents were allocated to either a 'yes', or 'no' category 'depending on whether they were regularly delivering training or not.

\section{Transfer of training - level of complexity}

This variable was measured using a five-item scale developed by the authors. The items were developed to capture perceptions of ability to transfer the learning acquired to new contexts including different resident/patient physical activity requirements and different conditions and impairments beyond what the trainees experienced during the training programme. This dimension of training transfer captures the trainees' ability to transfer learning to other contexts outside of the areas addressed on the training programme per se. Responses were given on a 5-point Likert scale with 1 rating their ability as poor and 5 rating their ability as excellent. Sample items included their perceived ability to 'accommodate new residents into sessions' and 'provide appropriate physical activities for residents with different impairments'.

A summary of the conceptual framework utilised in this study depicting the independent and dependent variables investigated is presented in Figure 1 below.

Figure 1. Model depicting the independent and dependent variables explored

$$
\begin{aligned}
& \text { Demographics } \\
& \text { - Age } \\
& \text { - } \quad \text { Background } \\
& \text { - Position } \\
& \text { Situational } \\
& \text { - Time since training } \\
& \text { - Employment tenure } \\
& \text { - Recruitment method } \\
& \text { - } \quad \text { Prep the intervention } \\
& \quad \text { training } \\
& \text { Organisational for } \\
& \text { - Size }
\end{aligned}
$$

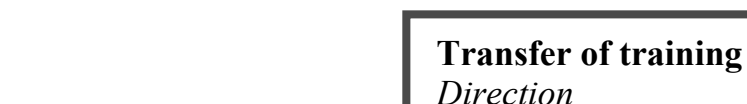

Direction

- Delivering activity sessions

- Regular delivery of sessions

Level of Complexity

- Perceived ability to transfer to new contexts

\section{Data analysis}

Due to the relatively small size of the sample base, the predominance of ordinal and nominal data and the presence of marked skewness and deviant scores identified during tests of normality, non-parametric tests were used to analyse the data. Non-parametric tests are not reliant on the manner of distribution of the sample population (Bryman and Cramer, 2005), and their use is recommended when the data does not meet the strict criteria required for parametric techniques (Pallant, 2007). The statistical analysis conducted on the data included correlation analysis utilising the Spearman's Correlation technique for interval data, the Chi Square technique for independence for nominal or ordinal data and standard multiple regression or direct logistical regression to identify which of the variables made the strongest contribution to predicting transfer of training in the public sector hospitals investigated.

\section{FINDINGS}

\section{Demographic, situational and organisational characteristics of respondents}

Respondents' ages ranged from 27 to 69 years with a mean age of 49 years (standard deviation $=7.9$ ). Employment length ranged from 3 to 37 years with a mean of 13.1 years (standard deviation $=7.6$ ). In terms of respondents' current position, nurses accounted for $28 \%$ (n. 32) of respondents; HCAs represented $30 \%$ (n. 35); physiotherapy 
assistants represented $14 \%$ (n. 16); $17 \%$ (n. 19) of the sample were made up of activity co-ordinators and 'other' represented $11 \%$ (n. 13). Where respondents chose to elaborate on the 'other' option, answers indicted an upward move to a more senior or management position. The average number of older residents per organisation ranged from eight to 420 residents with the mean number 58 (standard deviation $=64.6$ ).

Twenty-four percent (n. 27) of respondents indicated they volunteered to participate in the training programme, while $76 \%$ (n. 87) were approached by their line manager to attend the programme. Eighty-six percent (n. 99) of respondents indicated they had received sufficient information about the training programme prior to starting the training. Of the $13 \%$ (n. 16) who indicted they had not received sufficient information, $80 \%$ felt it did not impact negatively on their experience. Thirty-seven percent (n. 46) of respondents had completed their training between six and 36 months previously, while $63 \%$ (n. 78) completed their training between 37 and 60 months previously. Tables 1 and 2 below provide a summary of the frequency statistics, including a breakdown of sub groups for respondents' demographic and situational characteristics.

Table 1. Ranges and mean scores for age, employment tenure and organisation size

\begin{tabular}{lccccc}
\hline Variable & N. & Minimum & Maximum & Mean & $\begin{array}{c}\text { Standard } \\
\text { Deviation (S. D) }\end{array}$ \\
\hline \hline Age & 109 & 27 & 69 & 49.1 & 7.9 \\
Employment Tenure & 120 & 3 & 37 & 13.1 & 7.6 \\
Organisation Size & 96 & 8 & 420 & 57.9 & 64.6 \\
\hline
\end{tabular}

Table 2. Sub groups for the independent variables: age, employment tenure, time since training, position, recruitment method and organisation size

\begin{tabular}{|c|c|c|c|c|}
\hline Variable & Groups & Description & $\mathbf{N}$. & Frequency \% \\
\hline \multirow{3}{*}{ Age } & Gr. 1 & 20-39 Years & 13 & 11.9 \\
\hline & Gr. 2 & $40-49$ years & 45 & 41.3 \\
\hline & Gr. 3 & $50+$ years & 51 & 46.8 \\
\hline \multirow{3}{*}{ Employment tenure } & Gr.1 & Up to 10 years & 61 & 50.8 \\
\hline & Gr. 2 & $11-20$ years & 39 & 32.5 \\
\hline & Gr. 3 & $21+$ years & 20 & 16.7 \\
\hline \multirow{5}{*}{ Time since training } & Gr. 1 & Up to 2 years & 21 & 16.9 \\
\hline & Gr. 2 & 2-3 years & 25 & 20.2 \\
\hline & Gr. 3 & $3-4$ years & 20 & 16.1 \\
\hline & Gr. 4 & 4-5 years & 36 & 29 \\
\hline & Gr. 5 & $5+$ years & 22 & 17.7 \\
\hline \multirow{2}{*}{$\begin{array}{l}\text { Time since training - } \\
\text { Re-coded for regression } \\
\text { analysis }\end{array}$} & Gr. 1 & $6-36$ months & 46 & 37.1 \\
\hline & Gr. 2 & $37-60$ months & 88 & 62.9 \\
\hline \multirow{2}{*}{ Position } & Gr. 1 & $\begin{array}{l}\text { Activity co-ordinators and } \\
\text { physiotherapy assistants }\end{array}$ & 35 & 30.5 \\
\hline & Gr. 2 & HCAs, nurses and others & 80 & 69.5 \\
\hline \multirow[b]{2}{*}{ Recruitment method } & & Volunteered & 27 & 23.7 \\
\hline & & $\begin{array}{l}\text { Approached by } \\
\text { management }\end{array}$ & 87 & 76.3 \\
\hline \multirow{2}{*}{ Organisation size } & & $<50$ residents & 58 & 60.4 \\
\hline & & $50+$ residents & 38 & 39.6 \\
\hline
\end{tabular}




\section{Transfer of training}

\section{Transfer of training - direction}

Delivery of training intervention content (physical activity programmes) and regular delivery of training content

Sixty-eight percent (n. 84) of respondents were delivering the physical activity programmes developed as a consequence of their learning on the training intervention at the time of completing the questionnaire of which $70 \%$ (n. 59) were delivering the sessions on a regular basis (at least once per week). The mean number of sessions delivered per week was 2.37 (standard deviation $=1.42$ ). These results indicate that training has been transferred at some level on a consistent basis. Of the $32 \%$ of respondents who are no longer delivering sessions, $50 \%$ either never implemented them or stopped shortly after completing the intervention and $31 \%$ do not expect to resume delivering sessions in the future. Reasons cited for not transferring the training included: inability to release staff from other duties, appointed to new role within the organisation, or the activities are being delivered by another staff member.

\section{Transfer of training - level of complexity}

The mean score for respondents' perceptions of ability to transfer to new contexts was 3.34 (standard deviation $=.86$ ) where 1 represents poor ability and 5 represents excellent ability. This indicates that respondents consider their ability to accommodate new residents, residents with new medical conditions and residents with different levels of physical impairments or cognitive impairments in their activity sessions as between 'good' and 'very good'.

\section{Demographic, situational and organisational factors and training transfer}

The relationship between the eight demographic, situational and organisational factors and training transfer were explored independently and the significant findings are summarised below and presented in Table 3.

Table 3. Significant associations between independent variables and training transfer - direction

\begin{tabular}{|c|c|c|c|c|c|c|}
\hline & & Age & Background & Position & $\begin{array}{c}\text { Employment } \\
\text { Tenure }\end{array}$ & $\begin{array}{c}\text { Time since } \\
\text { Training } \\
\end{array}$ \\
\hline \multirow{4}{*}{ Delivering sessions } & $\mathrm{n}$. & & & 115 & 120 & \\
\hline & $\chi^{2}$ & & & $13.8^{1}$ & 7.16 & \\
\hline & $p$ & & & $.01^{*}$ & $.03^{*}$ & \\
\hline & phi. & & & .35 & -.24 & \\
\hline \multirow{4}{*}{ Delivering sessions regularly } & $\mathrm{n}$. & 79 & 82 & 82 & & 84 \\
\hline & $\chi^{2}$ & 9.2 & 6.91 & 12.1 & & 3.21 \\
\hline & $p$ & $.01^{*}$ & $.01^{*}$ & $.02^{*}$ & & $.01^{* *}$ \\
\hline & phi. & .34 & -.32 & .39 & & .40 \\
\hline
\end{tabular}

Age. A moderate association was found between 'age' and regular delivery of activity sessions utilising the Chi Square test for independence $(p=.01$, phi. $=.34)$; respondents aged between 40 and 49 years are most likely to deliver the activity sessions on a regular basis.

Background. A moderate relationship was observed between employee 'background' and regular delivery of the activities $(p=.009$, phi. $=-.318)$ with HCAs most likely to deliver the activities on a regular basis.

Employee position. A moderate relationship was found between 'employee position' and delivery status $(p=.008$, phi $=.346)$ and delivering on a regular basis $(p=.016$, phi. $=.385)$ utilising the Chi Square test for independence. Activity coordinators and physiotherapy assistants are more likely to deliver sessions on a regular basis than nurses or HCAs.

Employment tenure. A small relationship was observed between 'employment tenure' and delivery status $(p .=.028$, phi. $=-.244)$ with delivery status decreasing significantly for those in employment for $21^{+}$years utilising the Chi Square test for independence. Spearman's Correlation technique revealed a small association between duration of employment and perceptions of ability to transfer to different or new contexts (n. 100, $r=16, p=05$ ).

Time since training. This variable was moderately associated with regular delivery of the activities $(p=.010$, phi. $=.397)$ although the relationship was nonlinear. 
No association was observed between the 'organisation size', 'recruitment method' or the 'preparation for training' variables and training transfer at either level when measured independently.

Regression analysis was conducted to explore which of the eight independent variables being investigated are the best predictors of delivering the physical activity sessions, of delivering them regularly and of respondents' perceptions of ability to transfer to new or different contexts.

\section{Predictors of training transfer - delivery status}

Regarding the predicative ability of the eight factors investigated to predict delivery of activity sessions, the full model was statistically significant $(p=.042)$. The independent/covariate variables were shown to predict $73 \%$ of respondents correctly. The model as a whole explained between $17 \%$ (Cox and Snell R Squared) and $24.8 \%$ (Nagelkerke R Squared) of the variance in delivery status. However, only the variable 'current position' made a statistically significant unique contribution to the model $(p=.009)$ with an odds ratio of 17.67. Employees in the position of activity co-ordinator or physiotherapy assistant were 17 times more likely to report they are delivering sessions than nurses, HCAs and 'others'.

With regard to delivering the physical activity sessions on a regular basis, the full model was statistically significant $(p=.05)$. The independent/covariate variables were shown to predict $75 \%$ of respondents correctly. The model as a whole explained between $21.4 \%$ (Cox and Snell R Squared) and 30\% (Nagelkerke R Squared) of the variance in delivery status. No variable made a unique statistically significant contribution to the model. The summary results identifying the top four contributors for each dependent variable are presented in Table 4 .

Table 4. Logistical regression analysis predicting likelihood of reporting delivery and regular delivery of activity sessions - summary of top indicators

Logistical regression predicting employee delivery of activity sessions (yes or no)

\begin{tabular}{lcccccccc}
\hline Independent variables & B & SE & Wald & df & p & OR & \multicolumn{2}{c}{$\begin{array}{c}\text { L5\% of CI for OR } \\
\text { Higher }\end{array}$} \\
\hline \hline Age & -.038 & .045 & .737 & 1 & .390 & .962 & .881 & 1.051 \\
Background & -.293 & .646 & .206 & 1 & .650 & .764 & .210 & 2.648 \\
Employment position & 2.872 & 1.102 & 6.779 & 1 & $.009 * \star$ & 17.670 & 2.034 & 153.497 \\
Years employed & -.051 & .037 & 1.096 & 1 & .167 & .950 & .883 & 1.022 \\
\hline
\end{tabular}

Logistical regression predicting employee delivery of activity sessions regularly

\begin{tabular}{|c|c|c|c|c|c|c|c|c|}
\hline \multirow{2}{*}{ Independent variables } & \multirow{2}{*}{$\mathbf{B}$} & \multirow{2}{*}{ SE } & \multirow{2}{*}{ Wald } & \multirow{2}{*}{ df } & \multirow{2}{*}{$\boldsymbol{p}$} & \multirow{2}{*}{ OR } & \multicolumn{2}{|c|}{$\mathbf{9 5 \%}$ of $\mathrm{Cl}$ for OR } \\
\hline & & & & & & & Lower & Higher \\
\hline Background & .959 & .723 & 1.758 & 1 & .185 & 2.609 & .632 & 10.772 \\
\hline Employment position & 1.567 & .848 & 3.415 & 1 & .065 & 4.791 & .909 & 25.239 \\
\hline Preparation & .988 & 1.066 & .859 & 1 & .354 & 2.685 & .333 & 21.683 \\
\hline Time since training & .902 & .663 & 1.854 & 1 & .173 & 2.465 & .673 & 9.029 \\
\hline
\end{tabular}

Note: ${ }^{\star}=p<.05 ;{ }^{* *} p<.01$.

\section{Predictors of training transfer to new contexts}

With regard to predicting respondents' perceptions of ability to transfer to new contexts, the model is statistically significant $(p=.047)$. Three variables made a significant contribution to the model with 'method of recruitment' making the largest contribution (beta $=-.239, p=.05$ ) followed by 'age' (beta $=-.233, p=.049$ ) and 'number of years employed' (beta $=.218, p=.05$ ). The summary results identifying the significant contributors are presented in Table 5. 
Table 5. Multiple regression predicting perceptions of ability to transfer - summary of top indicators

\begin{tabular}{|c|c|c|c|c|c|}
\hline \multirow[b]{2}{*}{ Model No. } & \multirow[b]{2}{*}{ Variable } & \multirow[b]{2}{*}{ Beta } & \multirow[b]{2}{*}{$p$} & \multicolumn{2}{|c|}{$95 \%$ of $\mathrm{Cl}$ for OR } \\
\hline & & & & Lower & Higher \\
\hline & Age & -.233 & $.049^{\star}$ & -.051 & .000 \\
\hline & $\begin{array}{l}\text { Method of } \\
\text { recruitment }\end{array}$ & -.239 & $.045^{\star}$ & -.955 & -.012 \\
\hline & Years employed & .218 & $.05^{*}$ & -.001 & .050 \\
\hline \multicolumn{6}{|c|}{ Model was statistically significant: $p=.047^{\star}$} \\
\hline
\end{tabular}

Note: ${ }^{*}=p<.05$

In summary, results show that the predictors making the most significant contribution to the model varied according to the dimension of training transfer investigated. In relation to the direction of transfer of training, respondents' current position emerges as the best predictor of delivery status. For the level of complexity of training transfer, respondents' age, number of years employed and method of recruitment emerged as significant predictors of respondents' perceptions of their ability to transfer training to new or more complex contexts. Those respondents who were approached by management to take part in the intervention were most likely to have higher perceptions of their abilities to transfer to new contexts than those who volunteered.

\section{DISCUSSION}

Training transfer is an important dimension of training and development effectiveness. However, there is limited research exploring the nature and extent of training transfer or the factors which facilitate or hinder training transfer in organisations (Axtell et al., 1997). The limited studies on training transfer which exist report inconsistencies regarding the effect of demographic variables such as age, levels of education, job types and employment tenure on training transfer (Chen et al., 2006) in terms of both the direction and complexity levels of transfer.

This study found that respondents' age is significantly associated with transfer of training at the direction level. Employees aged 40-49 reported implementing training more frequently, as measured by the number of physical activity sessions delivered per week, compared with the younger or older employee age groups. The results might be explained by the fact that older respondents were likely to have accrued more years' experience working in the long-stay resident environment than younger respondents during which time they acquired personal and work related self-efficacy which facilitated them overcoming any obstacles to transfer. For example, Thijssen (1996), cited in Van der Klink et al. (2001), found older trainees with a broad variety of work experiences showed fewer problems achieving training goals and suggested they would probably face fewer problems with the application of training on the job. It may also be that the lower levels of transfer found among the oldest respondent group (aged 50 years or more) in this study is due to the more physically challenging nature of the work involved in implementing the training. If this were the case, it is worth highlighting that $47 \%$ of respondents reported being 50 years or over which may have implications for the selection process for different training programmes and job roles, according to the physical requirements of the programme.

The age profile of the employee respondents would appear to indicate an association between this type of setting and an older workforce which in turn has implications for the HRD function and the maintenance of human capital and the organisational intellectual assets. Where previous research had indicated that older trainees showed: less mastery of training material than younger adults (McEnrue, 1989, cited in Chen et al., 2006); experienced more difficulty applying training content on job (Van der Klink et al., 2001); and find it particularly challenging to develop new skills and knowledge (Chen and Klimoski, 2007), the current study found that age was not a barrier to developing new skills, transferring them into the workplace, maintaining them over time or generalising them to new contexts.

According to Chen et al. (2006), research that tests the effect of educational level on training effectiveness is sparse. In this study, respondents' background was found to be significantly associated with transfer of training at direction level. HCAs reported implementing training more frequently than nurses. Whilst it cannot be claimed that the findings in this study are generalisable to all programmes or contexts, they nonetheless demonstrate that in relation to the physical activity promotion training intervention, HCAs demonstrated higher levels of training transfer and sustained transfer than nursing staff. Consequently, the use of HCAs for this training intervention proved to be more cost effective in terms of sustained training transfer. 
The nursing qualification has a considerable academic dimension making nurses a more costly occupational group within the health service (McCabe and Garavan, 2008). In addition, staff shortages and the recruitment moratorium recently in place in the public sector has resulted in an increased workload and redeployment of nurses to nursing duties requiring their more specialist, medical and clinical skills. This study found that while those employees in the role of activity co-ordinators or physiotherapy assistants are reporting transferring training more frequently than those in the role of HCA or nurse, nurses are transferring training less frequently than the other three groups investigated. It is suggested, therefore, that more consideration is given to the use of less specialised or costly staff in the provision of some of the services, such as the physical activity promoting activities, to increase the sustainability of transfer which will ultimately increase the impact of the training at organisational level and the cost effectiveness of the HRD intervention.

With regard to employee position, it is worth noting that although the physiotherapy assistant is a role occupied by personnel at the level of health care assistant, the activity co-ordinators role in this study was occupied by individuals from both a nursing and HCA background. While the study found that those in the position of 'activity co-ordinator' were transferring training more frequently than the other positions, it did not investigate whether the background of the individual in the position of activity co-ordinator influenced training transfer.

Donovan et al. (2001) found employee tenure in an organisation particularly relevant to transfer; employees with more years of experience were more prepared for training, believed content to be more relevant and experienced more opportunities to transfer. In this study, implementation at direction level (delivery status) was found to decrease among those employed 20 years or more within the organisation. This may be a consequence of the more physically challenging nature of the work involved in implementing training or, redeployment to other duties correlated with increasing experience or, decreased interest in work and job enlargement with advancing years. The reasons for this decline were not explored within the study. However, employees with more employment experience had significantly higher scores for their 'perceptions of ability to transfer'. This has important implications for the HRD function and the ability of training and development programmes to develop human capital and affective competencies, even among the older or longest serving members of the workforce. In this instance, where employment tenure was found to be associated with delivery status and perceptions of ability to transfer to new contexts, it is argued that length of employment in the work environment enabled all participants, regardless of educational background, to acquire sufficient technical skills to achieve success.

The current study captured differences in time since completing the training intervention, ranging from 18 to 60 months, and training transfer. Time since completion of the training intervention is significantly associated with transfer of training at direction level although the pattern of transfer practice did not show the anticipated linear curve which might be expected. Whilst those trained up to two years previously demonstrated the highest level of regular transfer, the next most recent group (trained 2-3 years previously) demonstrated the lowest level of regular transfer. Interestingly however, $65 \%$ of respondents who completed training 5 years previously were implementing training on a regular basis compared to $39 \%$ of those who completed training 2-3 years previously. This level of transfer is higher than might be predicted by previous studies reported by Saks and Belcourt (2006). However, further studies are required to investigate if these findings are replicated across other training interventions within the same sector and settings. Reasons for the 'dip' amongst the 2-3 year post-training group were not explored. Furthermore, the results do not indicate whether performance or transfer variables 'dipped' during interim periods as found by Vermeulen and Admiraal (2009). Multiple checking points would be required to ascertain this information which was not undertaken in this study.

\section{Predicting levels of transfer according to demographic, situational or organisational factors}

When the effect of each of the eight demographic, situational or organisational variables was measured independently, the current position and employment tenure variables were both significantly associated with the dependent variable, delivery status. However, when all variables were regressed, the only significant variable was current position. With regard to their influence on regular delivery status, the four independent variables of age, background, current position and time since training were significantly associated when analysed independently. However, when the variables were regressed, no independent variable was significant although current position made the strongest contribution to the model.

With regard to the relative importance of eight demographic, situational or organisational factors on employee perceptions of ability to transfer to new contexts (transfer of training - level of complexity), the independent variables of age and employment tenure were significantly associated when analysed independently. However, 
when all eight variables were accounted for, method of recruitment, age and employment tenure were all significant.

With regard to delivery status, it is interesting to note that only the variable current position is the most significant contributor to the model and only at the basic level of transfer. At level of complexity, however, it is interesting to note that employees aged 40-49 years with longer years of service (employment tenure) and who were recruited by management for participation in the training intervention are significant predictors of employees positive perceptions in their abilities to transfer training to new or more complex contexts. Finally, although method of recruitment was not significantly associated with training transfer at any level when analysed independently, it is interesting to note its significance at level of complexity when all variables are accounted for. These results indicate that those who were approached by management were most likely to have higher perceptions of their abilities to transfer to new contexts than those who volunteered. These results would appear to suggest that management selection of employees for the training intervention over employee volunteering is the most successful option for transfer at higher levels of complexity.

\section{Limitations}

The model of the demographic, situational and organisational factors used in this study was more successful in predicting transfer at the level of complexity than at direction level. It is recognised that there are factors not included in the model for measuring training effectiveness which have been found to influence transfer including factors related to training programme design and delivery. It is also recognised that gaps remain in the literature with regard to the effects of other factors such as gender (Chen et al., 2006) which require further study.

Some of the findings appeared to indicate that training transfer was influenced by broader organisational factors associated with the transfer system than employee characteristics or acquired attributes. Future studies should consider the effect of the transfer system on levels of training transfer. They should also consider the effect of demographic and situational variables on perceptions of the effect of organisational system factors on training transfer.

Although a cross-sectional approach was used to investigate 102 organisations within the Irish healthcare sector, it should be recognised that health care systems are very complex with powerful subcultures (Natarajan, 2006) and even within the hospital sector, there are differences in function, cultures and structures. Consequently, it cannot be assumed that the findings in this study will generalise to all settings and sectors. Nonetheless, adopting this approach contributed to our understanding of the transfer process in this sector. Furthermore, the integrative model and processes used to operationalise the study can be adapted for use in other sectors.

\section{CONCLUSION}

This study investigated the relationship between demographic, situational and organisational variables on levels of training transfer. The results indicate that a number of the variables investigated significantly impacted on the different levels of training transfer within a specific healthcare setting. These findings are important as empirical research to date (e.g. Chen et al., 2006; Van der Klink et al., 2001) has not yet reached a consensus on how demographic variables relate to the training transfer process. The training transfer findings in the current study show that older workers can demonstrate high levels of trainability, employment experience can contribute to the effectiveness of training programmes, and finally, older employees have the ability to achieve sustained training transfer post-training. This is important where broader demographic and economic changes, both national and international, are impacting on the profile of the workforce to the extent that the workforce is ageing generally, the age of retirement is increasing and the average employee can expect to remain in the workforce for longer.

The results of this study have important implications for HRD practitioners with regard to the profile of the workforce in the type of setting where the study was conducted and the training and development function. In an ageing society where individuals will be required to remain in the workforce longer, employee skills and core competencies will need to be developed over the course of their employment. This has implications for trainee recruitment in terms of trainability, training transfer and job extension which in turn has the potential to impact on staff development and effective use of human resources within the organisation. The results of this study provide evidence of the trainability of older employees and the importance of employment tenure, job role and position in increasing training transfer and effectiveness. 
Axtell, C., Maitlis, S. and Yearta, S.K. (1997). 'Predicting immediate and longer-term transfer'. Personnel Review, 26, 201-222.

Baldwin, T.T. and Ford, J.K. (1988). 'Transfer of training: A review and directions for future research'. Personnel Psychology, 41, 63-105.

Bartlett, K. (2007). 'HRD and organisation commitment in health and social care organisations', in S. Sambrook, and J. Stewart (eds), Human Resource Development in the Public Sector. The Case of Health and Social Care, London: Routledge.

Brady, A. (2010). 'Delegation', in A. Brady (ed), Leadership \& Management in the Irish Health Service, Dublin: Gill \& Macmillan.

Brinkerhoff, R.O. (2005). 'The success case method: A strategic evaluation approach to increasing the value and effect of training'. Advances in Developing Human Resources, 7: 1, 86-101.

Bryman, A. and Cramer, D. (2005). Quantitative Data Analysis with SPSS 12 and 13: A Guide for Social Scientists, Routledge: London.

Burke, L.A. and Hutchins, H.M. (2008). 'A study of best practices in training transfer and proposed model of transfer'. Human Resource Development Quarterly, 19, 107-128.

Chen, G. and Klimoski, R.J. (2007). 'Training and development of human resources at work: Is the state of our science strong?'. Human Resource Management Review, 17: 2, 180-190.

Chen, H., Holton III, E. and Bates, R.A. (2006). 'Situational and demographic influences on transfer system characteristics in organizations'. Performance Improvement Quarterly, 19: 3, 7-26.

Cheng, E.W.L. and Ho, D.C.K. (2001). 'A review of transfer of training studies in the past decade'. Personnel Review, 30, 102-118.

Chiaburu, D.S. and Tekleab, G.A. (2005). 'Individual and contextual influences on multiple dimensions of training effectiveness'. Journal of European Industrial Training, 29: 8-9, 604-629.

Clarke, N. (2002). 'Job/work environment factors influencing training transfer within a human service agency: Some indicative support for Baldwin and Ford's transfer climate construct'. International Journal of Training and Development, 6, 146-162.

Clarke, N. (2007). 'The limitations of in-service training in social services', in S. Sambrook and J. Stewart (eds), Human Resource Development in the Public Sector. The Case of Health and Social Care, London: Routledge.
Colquitt, J.A., Le Pine, J.A. and Noe, R.A. (2000). 'Toward an integrative theory of training motivation: A meta-analytic path analysis of 20 years research'. Journal of Applied Psychology, 85, 678-707.

Conway, J., McMillan, M. and Becker, J. (2006). 'Implementing workforce development in health care: A conceptual framework to guide and evaluate health dervice rReform'. Human Resource Development International, 9, 129-139.

Curtis, E. (2010). 'Work motivation', in A. Brady (ed), Leadership \& Management in the Irish Health Service, Dublin: Gill \& Macmillan.

Department of Health and Children (2001). Effective Utilisation of Professional Skills of Nurses and Midwives: Report of Working Group. Dublin: The Stationery Office.

Department of Health (2012). Future Health: A Strategic Framework for Reform of the Health Service 20122015. Dublin: The Stationery Office.

Donovan, P., Hannigan, K. and Crowe, D. (2001). 'The learning transfer system approach to estimating the benefits of training: empirical evidence'. Journal of European Industrial Training, 25, 221-228.

Elangovan, A.R. and Karakowsky, L. (1999). 'The role of trainee and environmental factors in transfer of training: An exploratory framework'. Leadership and Organisation Development Journal, 20, 268276.

Gregoire, T.K., Propp, J. and Poertner, J. (1998). 'The supervisors role in the transfer of training'. Administration in Social Work, 22: 1, 1-18.

Hutchins, H.M. (2009). 'In the trainers voice: A study of training transfer practices'. Performance Improvement Quarterly, 22: 1, 69-93.

Keogan, J.K. (2006). 'Management of health services in Ireland: Identifying the determinants of process effectiveness in health related services'. Paper presented at Irish Academy of Management Conference, University College Cork, $6^{\text {th }}-8^{\text {th }}$ September 2006.

Lave, J. and Wenger, E. (1991). Situated learning: legitimate peripheral participation, Cambridge: Cambridge University Press.

Lim, D.H. and Johnson, S.D. (2002). 'Trainee perceptions of factors that influence learning transfer'. International Journal of Training and Development, 6, 36-48.

McCabe, T.J. and Garavan, T.N. (2008). 'A study of the drivers of commitment amongst nurses: The salience of training, development and career 
issues'. Journal of European Industrial Training, 32, 528-568.

McKenna, H.P., Hasson, F. and Keeney, S. (2004). 'Patient safety and quality of care: The role of the health care assistant'. Journal of Nursing Management, 12, 452-459.

Martinez, J. and Martineau, J. (1998). 'Rethinking human resources: An agenda for the millennium'. Health Policy and Planning, 13, 345-358.

Natarajan, R.N. (2006). 'Transferring best practices to healthcare: Opportunities and challenges'. The TQM Magazine, 18, 572-582.

Pallant, J. (2007). SPSS Survival Manual Third Edition, Australia: McGraw Hill Open University Press.

Rondeau, K.V., Williams, E.S. and Wagar, T.H. (2009). 'Developing human capital: What is the impact on nurse turnover?'. Journal of Nursing Management, $17,739-748$.

Russ-Eft, D. (2002). 'A typology of training design and work environment factors affecting workplace learning and transfer'. Human Resources Development Review, 1, 45-65.

Saks, A.M. and Belcourt, M. (2006). 'An investigation of training activities and transfer of training in organisations'. Human Resource Management, 45, 629-648.

Sambrook, S. and Stewart, J. (2007). 'HRD in health and social care', in S. Sambrook and J. Stewart (eds), Human Resource Development in the Public
Sector. The Case of Health and Social Care, London: Routledge.

Santos, A. and Stuart, M. (2003). 'Employee perceptions and their influence on training effectiveness'. Human Resource Management, 13, 27-45.

Tannenbaum, S.I., Cannon-Bowers, J.A., Salas, E. and Mathieu, J.E (1991). 'Factors that influence training effectiveness: A conceptual model and longitudinal analysis'. Technical Rep. No 93-011. Orlando, FL: Naval Training Systems Centre.

Tharenou, P., Saks, A.M. and Moore, C. (2007). 'A review and critique of research on training and organisational-level outcomes'. Human Resource Management Review, 17, 251-273.

Van der Klink, M.R., Gielen, E.E.M. and Nauta, C. (2001). 'Supervisory support as a major condition to enhance transfer'. International Journal of Training and Development, 5, 52-63.

Valeda, R., Caetano, A., Michel, J.W., Lyons, B.D. and Kavanagh, M.J. (2007). 'The effects of training design, individual characteristics and work environment on transfer of training'. International Journal of Training and Development, 11, 282-294. Vermeulen, R. and Admiraal, W. (2009). 'Transfer as a two-way process: Testing a model'. Journal of European and Industrial Training, 33: 1, 52-68.

Warr, P. and Bunce, D. (1995). 'Trainee characteristics and the outcomes of open learning'. Personnel Psychology, 48, 347-375. 